\title{
As mudanças nas relações entre a sociedade e o Estado e a tendência à anomia nos movimentos sociais e nas organizações populares
}

JOSÉ DE SOUZA MARTINS

$\mathrm{T}$ UDO PARECE indicar que estamos entrando numa fase da história social e política do país marcada por algumas inversões na relação entre a sociedade civil e o Estado. A história do Brasil independente tem sido uma história de tutela do Estado sobre a sociedade, sociedade cujos marcos históricos resultam de processos que fluem lentamente e cujas mudanças apenas lentamente chegam à consciência da maioria de seus membros, mesmo daqueles que na militância política transformadora podem estar mais perto da sua compreensão. Circunstâncias próprias do período ditatorial recente despertaram as possibilidades criativas da sociedade em face do Estado. Disseminaram-se os movimentos sociais e as organizações populares e tudo sugeria, e ainda sugere, uma fase nova de nossa história social marcada pelo protagonismo da sociedade. No entanto, essa curta vivacidade social parece estar entrando em crise, diante de um Estado que foi mais ágil na definição das circunstâncias do agir histórico.

Para quem tem acompanhado o surgimento e a atuação dos movimentos sociais, e neles os dos chamados movimentos populares, essa inversão propõe a necessidade de uma compreensão não só das mudanças, mas do lugar desses movimentos na nova situação e no novo cenário político que se abriu com o fim da ditadura. Se essa tendência se confirmar, esses movimentos vão se tornar anômicos, do que, aliás, já existem não poucas evidências: suas referências ideológicas não correspondem à circunstância histórica nem às possibilidades de intervenções transformadoras que nela se abrem.

A inversão e a anomia poderão decorrer do incremento no conservadorismo da sociedade e do seu atraso em relação às possibilidades históricas abertas em favor da sociedade pelo Estado reduzido em sua abrangência ou, ao menos, modernizado. É certamente motivo de apreensão que a sociedade e seus agentes compreendam mal o possível histórico deste momento, sobretudo porque, recuando o Estado em suas tarefas substitutivas da sociedade, cria-se um âmbito desregulamentado da vida social e política que 
tende a favorecer grupos de direita e até extremismos, na falta de uma intervenção efetiva, universalista, construtiva e menos retórica de grupos e partidos de esquerda.

O que foi a crise do Estado durante a ditadura e crise do Estado ditatorial na sua fase final, quando os setores liberais das oligarquias se autonomizaram em relação ao partido governante, é agora a crise da sociedade civil, na sua dificuldade para dar o passo político que a circunstância lhe pede. Resta saber se os movimentos sociais e as organizações que em nome da sociedade falam e agem têm condições, a curto prazo, de compreender sua refuncionalização decorrente das mudanças recentes. Impasses aparentemente sem sentido entre a sociedade e o Estado sugerem haver dificuldades para o desenvolvimento dessa compreensão e esse é o ponto problemático que motiva estas considerações.

No tempo da ditadura, a sociedade inorganizada e privada de sua expressão política plena combateu o Estado autoritário, muitas vezes em nome de interesses particularistas, os interesses de grupos singulares e nem sempre majoritários, como a classe operária, os trabalhadores rurais, os jovens da classe média, grupos femininos e feministas, grupos de vizinhança e moradores etc. A sociedade habituada à dominação populista teve que construir aos poucos a compreensão do seu lugar subalterno em face do Estado e dos limites institucionais da circunstância histórica às suas reivindicações.

O surgimento dos movimentos sociais, urbanos e rurais, fora de enquadramentos partidários, foi de certo modo uma grande novidade na sociedade brasileira, uma nova forma de expressão social que se combinou com o florescer de novos sujeitos sociais e políticos. As restrições partidárias viabilizaram a emergência de protagonistas do enredo histórico que o populismo das décadas anteriores havia sepultado na vala comum dos beneficiados antecipadamente pelo Estado provedor. Todas as demandas sociais ganhavam expressão e solução nas antecipações dos governantes e dos políticos.

Mesmo demandas que se tornariam explosivas no período ditatorial e sobretudo no período pós-ditatorial, como a da reforma agrária, não expressavam de fato as verdadeiras necessidades dos pobres do campo. Eles estiveram, em grande parte, acomodados num sistema de cooptação e paternalismo que os conservara na conveniente subserviência e no conformismo de um regime de trabalho resultante de tentativas de acerto e erro, verdadeiros experimentos a assegurar a legitimidade de um longo período de transição do trabalho escravo para o trabalho livre. 
O discurso da reforma agrária era localizado e constituía um modo de enquadrar e dar sentido político a uma justa reivindicação imediata de sobrevivência, que se perdia em conflitos de natureza policial e arranjos locais e localizados. Correspondia muito mais a uma visão dos problemas sociais de setores radicais da classe média, na esquerda e também na direita, do que propriamente ao que pensavam e pensam, e precisam, as diferentes e desencontradas categorias de trabalhadores rurais: meeiros, parceiros, posseiros, minifundistas, braçais temporários ou permanentes. Não por acaso, o vocabulário dessas lutas, como agrário, camponês, latifúndio, burguesia etc., é um vocabulário historicamente ausente do nosso mundo rural, palavras que não expressam de fato os conflitos e as polarizações sociais, que fluem de outro modo e por outros modos de tomar consciência das contradições sociais. O vocabulário da luta não coincide com o vocabulário da vida, o que quer dizer que a consciência da luta é diversa da consciência de quem quer dirigir a luta. Esse distanciamento tem sido próprio das lutas camponesas em muitos países, conseqüência das peculiaridades históricas dessa categoria social, como dizia Marx, mas também conseqüência da impotência própria da indefinida classe social que quer dirigir as outras classes, que é classe média e nela a intelectualidade iluminista, que ele era e não disse.

Os problemas sociais do campo encontrariam resposta e solução numa muito pouco definida reforma social que seria a reforma agrária. Até hoje, a classe média militante, os setores radicais dessa classe, procuram de distintos modos enquadrar os problemas do campo e dos trabalhadores rurais na questão agrária e propor-lhe como solução uma reforma agrária que depende de extensos prólogos para que se defina o que afinal é a reforma agrária. Descolamento próprio de uma reivindicação mediada por interesses e concepções de uma categoria social diferente da categoria ou das categorias em nome das quais a reivindicação ou a pressão é feita. Esse desencontro, que é grave, é a base do que estou chamando de tendência à anomia no caso dos movimentos populares no campo. Isso não invalida a motivação iluminista da classe média que, com razão, se inquieta com a pobreza e as más condições de vida das populações pobres. Mas, essa intervenção complica o próprio anseio de justiça das vítimas de um longo processo de desenvolvimento econômico excludente, à medida em que as fantasias cultivadas pela classe média sobre a pobreza, ainda que generosas, estão descompassadas em relação ao mundo de quem é objeto da reivindicação.

Não é estranho, portanto, que os interesses dos diferentes grupos desigualmente atingidos por diferentes intervenções do governo ditatorial, em diferentes momentos, tenham se manifestado como interesses particularistas, sem conexão uns com os outros. A demora na aglutinação 
desses particularismos teve como causa a heterogênea intervenção espoliativa ou repressiva do Estado ditatorial nos diferentes setores da sociedade, da economia e da política.

A ditadura militar não foi, no entanto, um bloco político coeso e coerente. As cassações políticas não ocorreram de vez, foram se sucedendo, encerradas, reabertas, encerradas novamente, sempre em função de providências repressivas tópicas. Por seu lado, a política fundiária se cumpriu como exceção e não como regra, contraditoriamente combatendo o latifúndio nas áreas de tensão social e, ao mesmo tempo, gestando o latifúndio de empresa em novas regiões, o que simultaneamente produzia novas tensões. Enquanto fazia a reforma agrária tópica de cunho militar e repressivo, por razões de segurança nacional, o Estado atendia à demanda dos movimentos sociais locais, precários, surgidos na emergência de conflitos inesperados, e ao mesmo tempo reprimia, prendia e processava as lideranças e apoiadores desses movimentos. Um reconhecimento confuso de um fato histórico verdadeiro, o de que os agentes da luta política pela reforma agrária não eram necessariamente os mesmos que dela necessitavam.

Mas, houve uma certa articulação dos particularismos, menos por consciência e projeto próprios e mais porque o antagônico é que assegurava a unidade relativa das oposições. Gestou-se aí um oposicionismo residual, uma coalisão dos resíduos da repressão e do autoritarismo, sem o qual teria sido impossível a superação do regime militar e a transição para um Estado democrático. Era a mediação do adversário, o Estado ditatorial, que garantia a força das oposições, embora tendessem elas a ser um conjunto de corporativismos. Essa articulação veio de fora, de grupos institucionais extrapartidários mais amplos e nem sempre enraizados na situação social daqueles em nome dos quais reivindicavam. Até hoje, muito do debate sobre a reforma agrária expressa essa desconexão entre a situação dramática de quem dela precisa e a imprecisa consciência que dela tem os que a reivindicam em nome dos que são dela necessitados.

Foi extraordinário o papel que a Igreja teve e continuou tendo nessa articulação, com suas pastorais sociais, como a pastoral indígena, a pastoral da terra, a pastoral do trabalho. Elas foram corretamente definidas pelos bispos como pastorais de suplência, mero socorro temporário. As tensões sociais e políticas recrudescidas na ditadura ganhavam um rosto, um protagonista, na mediação pastoral. O clamor popular, como com justeza definiram os bispos num de seus documentos, valia-se do aparato da Igreja, de seus canais de expressão e comunicação, único modo de exprimir-se num país em que a expressão política radical, que tocava nos problemas de raiz, era considerada crime. 
Mesmo os partidos políticos clandestinos procuraram abrigo sob o manto protetor da Igreja. Membros de partidos oficialmente ateus o fizeram. Partidos ou tendências, como eram chamados, com atuação restrita e sem maior alcance, ganharam espaço por esse meio, ampliaram sua atuação valendo-se da penetração popular da Igreja, da legitimidade que, de certo modo, conservou durante a ditadura. No geral, quase todos esses grupos desdenhavam esse papel da Igreja. Baseavam-se na suposição de que tudo que não fosse partidário e partidariamente de esquerda despolitizava e atrofiava as demandas sociais, confinando-as em quadros ideológicos impróprios para a ação política.

Um certo aparelhismo tomou conta dessa mediação impolítica que cumpria uma função, sem dúvida, política. O resultado foi a busca da laicização da ação dos grupos de Igreja e até mesmo a sua institucionalização como grupos seculares, como foi o caso do MST - Movimento dos Trabalhadores Rurais Sem Terra, convertidos em grupos semipartidários. Houve grande resistência, até mesmo por parte dos bispos, quando a oportunidade se apresentou, em constituir um Partido Católico no Brasil, coisa que teria sido possível. Com isso, os católicos passaram a expressar-se por meio do partido de oposição à ditadura e nele de preferência por meio das tendências ditas de esquerda. Foi assim até o surgimento do Partido dos Trabalhadores, que herdou a maior parte desses parasitismos, desses aparelhismos, embora não todos.

Ao menos no que se refere às lutas sociais no campo, bem antes do final da ditadura e nos dias anteriores à reunião do episcopado que lançou o documento Igreja e Problemas da Terra, em 1980, uma definição de princípios e concepções sobre a questão agrária e a reforma agrária, o Estado demonstrou que estava dando passos na direção de um reconhecimento do papel histórico dos grupos comunitários e das novas formas de atuação da sociedade. Coincidindo com a primeira visita do Papa, o general Golbery do Couto e Silva, ideólogo do regime, em discurso na Escola Superior de Guerra, sublinhou o risco político e a anomalia de uma sociedade que passara a expressar suas demandas por canais não-partidários, como era o caso da Igreja. Portanto, antes mesmo que o regime militar se extinguisse, o Estado brasileiro tomava consciência das mudanças na relação entre a sociedade e o Estado e se propunha a reconstituir a hegemonia do Estado, mediante a abertura política, de modo a incorporar a nova vitalidade social como um fator politicamente positivo e administrável. Isto é, o Estado se abria para a possibilidade de fazer da sociedade um agente auxiliar, de modo a eliminar o conflito entre ambos, agravado pelo próprio regime. Mas, essa era ainda a concepção do Estado centralizado, lógica das nossas ditaduras, que enquadra, tutela e dirige a sociedade. 
Sem dúvida, gestava-se aí, ainda que de modo confuso, o reconhecimento das mudanças nesse relacionamento que, de outros modos, ocorria em outros países, sobretudo nos países hegemônicos, em conseqüência do nem sempre corretamente chamado de neoliberalismo. Lembro, muito de passagem, a reemergência das nacionalidades em países como a Espanha, a Grã-Bretanha, entre outros, e o reconhecimento de sua legitimidade política, depois de décadas de sufocamento e até de repressão. No nosso caso, o equivalente foi o reconhecimento, mesmo durante o regime militar, da realidade própria das populações indígenas e de seus direitos territoriais e da legitimidade das reivindicações territoriais das populações rurais mediante o Estatuto da Terra e da não-intervenção na Contag - Confederação Nacional dos Trabalhadores na Agricultura. É claro que o Estado impôs, também, a legitimidade de sua soberania sobre as providências relativas à questão do território, como um ponto além do qual não admitia ultrapassagem.

Vencida a ditadura, o Estado se tornou liberal ou retornou ao seu liberalismo de base municipal e localista, aparentemente revitalizando as tradições oligárquicas. De certo modo, cumpria-se uma vez mais na história republicana o movimento pendular entre centralização política e descentralização, entre o absolutismo republicano e a federação oligárquica, entre a ditadura e a democracia (1). Mas, o Estado defrontou-se com a sociedade mobilizada, expressando-se por meio dos movimentos sociais e das organizações populares. Os limites, aliás, da força política desses novos sujeitos fizeram-se ver na campanha pelas diretas-já. De um lado, porque os novos sujeitos não se revelaram em condições de agir autonomamente. Tiveram que aliar-se a outros setores, tradicionais, da sociedade, setores de classe média e de tradição liberal e colocar-se sob sua hegemonia. Ficou claro que esses novos sujeitos não tinham condições de exercitar um protagonismo hegemônico e decisivo. Mas, ao mesmo tempo, os movimentos sociais e as organizações populares haviam passado a carregar o ônus do aparelhismo dos grupos partidários que durante a ditadura não tiveram condições de atuar com identidade própria. Tornaram-se cativos de concepções políticas hierárquicas e corporativas que comprometiam justamente sua novidade e sua criatividade. Os movimentos sociais, ao se deixarem aparelhar pelos partidos, dessacralizaram a esperança.

Enquanto o Estado se abriu num liberalismo peculiar, expressão também da sua fragilidade em face do pacto político de antagônicos que viabilizara o fim da ditadura, a sociedade civil foi se tornando, rapidamente, corporativa e autoritária. Os movimentos sociais tornaram-se organizações, não raro agressivas, autoritárias e intolerantes, com burocracia própria, bloqueando o espaço para novos e autênticos movimentos sociais. Os 
particularismos se enrijeceram, não evoluíram em direção aos valores universais que sua prática anunciava, não perceberam a dimensão adequada de sua prática.

No limite, os movimentos sociais e as organizações populares passaram a negar a política, o debate e a corresponsabilidade, que seriam próprios da sociedade civil que tivesse evoluído na direção de assumir o fortalecimento da sociedade em face do Estado. Ao contrário, organizam-se como Estado (o PT, um partido que em grande parte representa organizações populares e sindicais, e seu gabinete paralelo; o MST e seu empenho em estabelecer uma soberania particularista nas porções do território que presume conquistar, no pressuposto de que são territórios liberados, similar ao que fundou a ação do PCdoB nos anos 50).

Não assumem esse confronto como confronto entre sociedade civil e Estado que contenha a possibilidade histórica do fortalecimento da sociedade civil e sua definição como protagonista da versão moderna da inclusão social dos pobres como agentes do próprio destino. Uma sociedade civil diversificada quanto à composição das classes sociais que, ao se tornar progressivamente a categoria que protagoniza o processo histórico e lhe dá direção, retira do Estado grande parte de seu conteúdo específico de classe e o torna menos dirigente e mais serviço à sociedade. Algo parecido com o que a Igreja Católica, em países como o Brasil, diz ser e procura ser.

Boa parte da dificuldade vem dos reducionismos interpretativos que atravessaram a prática desses híbridos movimentos sociais e organizações populares, também influenciados fortemente pelas igrejas. A Igreja Católica e algumas igrejas protestantes elegeram o pobre e desvalido como o sujeito da história do presente, como a figura humana cujas carências põem em evidência os riscos que um regime econômico degradante impõe à condição humana e aos valores universais do homem e da humanização do homem. É nesse plano que se aproximam dos partidos políticos de esquerda tradicionais. Apesar da justeza dos valores desse quadro de referência, esse pobre é uma abstração. Não levamos em conta que no mundo contemporâneo há uma grande diversidade de pobrezas, muito além da mera pobreza do essencial à sobrevivência física da pessoa. O pobre desse imaginário social é um pobre esquálido e fotográfico, que também existe, infelizmente, em muitos lugares do mundo - um pobre abaixo da linha da miséria, mas também abaixo da linha da participação ativa nos destinos da sociedade. Uma sociedade de miseráveis não é uma sociedade de cidadãos nem pode sê-la. 
Nas gradações da pobreza é preciso reconhecer que muitos são pobres não porque padeçam privações materiais do essencial à sobrevivência. A criatividade popular tem gestado estratégias de sobrevivência que perturbam a lógica econômica dominante e oferecem saídas onde os técnicos e economistas não vêm saída alguma. A pobreza moderna é maior e bem diversa da pobreza definitiva de um imaginário religioso ou de uma classe média em que o pobre está reduzido a um esquálido esquema de interpretação social e política. O essencial da pobreza moderna e capitalista está na transformação do homem em coisa, na sua desumanização. Na sociedade capitalista é pobre quem é pobre de humanidade. Quando a pobreza material e alimentar o atinge, estamos apenas em face da extrema exacerbação da coisificação do ser humano: ele se tornou descartável, sua vida já nem mesmo vale o bocado de comida que come - a máquina da produção de riqueza não tem para ele lugar e não o tem sobretudo porque o priva de participação no universo utópico da esperança. No geral, as igrejas vêm se afastando completamente do ideário social da esperança e vão sendo cooptadas por um ideário materialista pobre e sem sentido, mesmo entre aqueles que nelas se consideram progressistas.

Aos que crêem, quase que se poderia lembrar que Deus não está essencialmente no particularismo do bocado, mas na universalidade da boca que se alimenta, que também fala, mesmo quando não tem o que comer. $\mathrm{E}$ ao falar expressa uma consciência, o espírito, a consciência utópica de que o comer é subsidiário do falar e do pensar, do querer e do transformar. A boca que apenas come é a boca pobre, não necessariamente a boca dos pobres. A boca que apenas come é a boca imaginada pela consciência instrumental do militante político que não pode falar a fala de sua própria classe, oscilante e indefinida, por isso usurpa a classe alheia e a consciência alheia, dos trabalhadores e dos pobres, para falar em nome deles, no lugar deles, o que não é o que eles necessariamente precisam e querem. O radicalismo dessa usurpação não expressa nem mesmo as necessidades radicais da sociedade (2), quanto mais as necessidades dos pobres. Pode-se mesmo dizer que nessa infernal inversão, os pobres são excluidos porque foram excluidos e privados do direito de falar por si mesmos, vítimas da palavra usurpada no discurso préfabricado e divorciado da práxis de uma classe média com fortes tendências autoritárias, mesmo quando se proclama revolucionária e identificada com o sagrado princípio da liberdade de consciência.

Transformações que estão ocorrendo nas próprias igrejas que, obviamente, não são corpo distinto da sociedade, indicam claramente essas gradações da pobreza. Os que se incomodam, até com razão, com a liturgia da dança que tem se difundido nas cerimônias religiosas, esquecem que ela 
representa grave e significativa crítica da pobreza teológica. Nela se nega e se critica explicitamente a concepção de que o corpo flagelado dos pobres é um corpo santo, de que na pobreza está a santidade. A idéia do corpo pobre como corpo santo é uma sisuda idéia monástica acentuadamente em conflito com a concepção popular de que o corpo santificado e bendito é o corpo farto e alegre e não o corpo carente. Nessas novas tendências, que se desenvolvem nos vazios deixados pelo maniqueísmo religioso e político, o corpo se reconcilia com a fé à medida em que restituem ao corpo a alegria de um corpo destinatário da vida e não apenas da política.

O amplo espaço de manifestação da sociedade civil do período pósditatorial não foi decididamente ocupado. Só poderia sê-lo pela sociedade organizada e atuante, isto é, pela festa e pela alegria. Ao invés disso, os agentes do protagonismo popular se distanciaram dessa possibilidade, recuaram para posições populistas e de patronagem. Foram ficando confinados no pequeno território que sobrou para o protagonismo da pobreza. Curiosamente, o pobre deixou de ser o pobre genérico, a vítima genérica do desenvolvimento capitalista, para se tornar apenas o pobre residual-o excluído, o desempregado, o de poucas oportunidades, não a maioria, não o pobre que somos, mas o pobre de quem temos pena. Por isso, a população pode generosa e comovidamente apoiar muitas das justas manifestações do MST e na eleição seguinte votar em candidatos que representam justamente o latifúndio e a dominação oligárquica.

A esses desencontros juntem-se outros. O setor da Igreja que conciliava ou concilia o discurso sobre o pobre com uma prática encarnada foi sendo dilacerado pelo reducionismo da exclusão. Isso abriu um distanciamento progressivo entre os bispos e as comunidades de base. Ao se tentar dar uma dimensão política às CEBs, deu-se, na verdade, uma dimensão partidária, num país em que as esperanças das populações que podem ter uma identidade nas CEBs poderiam, também, expressar sua vontade política por meio de vários e não só de um partido político - do PT ao PSDB, passando por partidos como o PDT, o PSB, o PPS, entre outros. Esse seqüestro ideológico e político fez com que as vanguardas das esquerdas populares avançassem mais depressa do que as bases, fez com que os grupos de mediação ficassem sozinhos lá adiante, separados do povo e da maioria dos bispos. Caíram na armadilha da incompreensão, divorciaram a teoria da prática, que parece caminhar para a impossibilidade de uma reconciliação.

Esse fechamento anuncia e propõe o Estado centralizado e autoritário como expressão da vontade social e, por ele, a sociedade subjugada, e não o contrário, que seria o Estado a serviço de uma sociedade civil soberana, consciente, pluralista, moderna. Todas as indicações são de que movi- 
mentos e organizações populares, e partidos com eles identificados, não percebem a alternativa e o espaço de ação que está aberto, que desloca o protagonismo da História do Estado para a sociedade. E obviamente isso só tem sentido numa sociedade complexa, pluralista e democrática, na qual a diferença dos particularismos, como os que caracterizam hoje os nossos movimentos sociais e as nossas organizações populares, ganha força política e legitimidade histórica na possibilidade das coalisões e dos valores universais e históricos referidos ao bem comum. Exatamente o oposto do que vem acontecendo.

O amplo território da liberdade, da democracia e da sociedade como agente do querer histórico, vem se abrindo desde o fim da ditadura em conseqüência justamente da ação dos movimentos sociais e das organizações populares. Mas, também, em conseqüência do amadurecimento político dos grupos sociais e políticos de centro, dos liberais, da esquerda independente e até mesmo de setores das oligarquias que se modernizaram nas últimas décadas e revalorizaram seu liberalismo enraizado nas tradições ideológicas e políticas do século XIX, quando eram a esquerda do regime monárquico. É o território que possibilita fazer da sociedade uma sociedade ativa na gestão dos direitos e da qualidade de vida, basicamente o município e os grupos comunitários. Esse território vem sendo desdenhado (3) e abandonado à iniciativa de outros grupos que, aliás, constituem um fato positivo na presente circunstância histórica: uma diveita civilizada, conservadora em algumas questões, liberal em outras, que se propõe democraticamente, em bases modernas, a disputar a possibilidade da co-gestão local da relação entre a sociedade e o Estado com os grupos de esquerda e com uma direita remanescente do governo militar, que tende ao populismo, à repressão e não raro à corrupção.

Os movimentos sociais e as organizações populares, que têm suas raízes históricas nas reivindicações e nos embates do período ditatorial, parecem engessados na moldura dos confrontos de então, enquanto a sociedade e o Estado se transformam mais depressa do que podem perceber. Esses grupos afundaram numa prática própria do tempo da ditadura, a de desestabilizar o governo e precipitar crises institucionais, questionando sua legitimidade. Só que agora podem vir a ser governo (e já estão sendo em municípios e estados). Minam, portanto, sua própria legitimidade política. Em grande parte, porque as referências ideológicas desses grupos e dos grupos de mediação que os apóiam e orientam são referências construídas estritamente na suposição de que todos os conflitos são conflitos de classes, na suposição simplificadora de que o confronto político da época da ditadura era um grande e final confronto entre o proletariado e a burguesia, entre o bem e o 
mal. Deriva daí, no meu modo de ver, o notório messianismo hoje subjacente à ação desses movimentos e organizações, na espera de um presidente-messias que instituirá, finalmente, a república de Belo Monte, suprimirá a política e alimentará os pobres com o pão nosso de cada dia e o ideológico fundamentalismo que tornará a política inteligível, a sociedade dócil e punirá com espada de fogo os que inadvertidamente cumpriram como foi possível a missão que a História lhes reservou ao longo do tempo.

É evidente a anomia desse mal disfarçado sebastianismo. A enorme riqueza de uma prática criativa, que tem sido a desses grupos e movimentos, perde-se na ideologia descompassada e desenraizada que não está a ela referida, que não a traduz em consciência social e projeto histórico. Antes, a afasta de sua vitalidade e da rica consistência do historicamente possível que ela própria tem aberto. Esse messianismo ideológico dessacraliza a mística dos movimentos populares e corrói o carisma de suas lideranças. Destrói, portanto, a utopia que eles encerram e vai deixando, assim, de ser a referência crítica que renova e fundamenta a práxis.

\section{Notas}

1 A idéia do movimento pendular no processo político brasileiro encontra-se em Victor Nunes Leal, Coronelismo, enxada e voto, $2^{\text {a }}$ ed. São Paulo, Alfa-ômega, 1975, passim.

2 Segundo Heller, são radicais as necessidades sociais que não podem ser satisfeitas sem profundas transformações sociais. Cf. Ágnes Heller, La théorie des besoins chez Marx, trad. Martine Morales. Paris, Union Générale d’Éditions, 1978.

3 Zander Navarro sublinha esse desdém em texto relativamente recente. Cf. Zander Navarro, Politicas públicas, agricultura familiar e os processos de democratização em áreas rurais brasileiras (com ênfase para o caso do Sul do Brasil). Texto apresentado no Grupo de Trabalho sobre Processos Sociais Agrários, no XX Encontro Anual da Associação Nacional de Pós-Graduação e Pesquisa em Ciências Sociais (ANPOCS), Caxambu (MG), 22 a 26 de outubro de 1996, p. 20 (nota).

José de Souza Martins é professor do Departamento de Sociologia da Faculdade de Filosofia, Ciências e Letras da USP. 